\title{
O SETOR PORTUÁRIO SERGIPANO E SUA DINÂMICA RECENTE: TRANSPORTE DE CARGAS E GARGALOS INFRAESTRUTURAIS
}

Nelson Fernandes Felipe Junior ${ }^{1}$

\section{Resumo}

O transporte marítimo contribui com os fluxos de mercadorias no espaço e permite articular diversas cidades, regiões e países, sendo importante para o desenvolvimento econômico. $\mathrm{O}$ estado de Sergipe apresentou maior inserção econômica em âmbito regional e nacional na última década, no entanto, possui um setor portuário pouco dinâmico que prejudica o comércio, as redes e o efeito multiplicador interno. Diante desse contexto, busca-se realizar uma análise setorial, considerando a relação entre transporte marítimo, logística e dinâmica econômica, além de destacar os principais gargalos existentes.

Palavras-chave: setor portuário, transporte marítimo, mercadorias, gargalos.

\section{THE SERGIPANO PORT SECTOR AND ITS RECENT DYNAMICS: LOADS TRANSPORT AND INFRASTRUCTURE BOTTLENECKS}

\begin{abstract}
Maritime transport contributes to the flow of goods in space and allows connecting cities, regions and countries and is important for economic development. The state of Sergipe presented a greater economic insertion in the regional and national scope in the last decade, however, it has a port sector that is not very dynamic, which damages trade, networks and the internal multiplier effect. In this context, we intend to carry out a sectoral analysis, considering the relationship between maritime transport, logistics and economic dynamics, besides highlighting the main existing bottlenecks.
\end{abstract}

Keywords: port sector, maritime transport, goods, bottlenecks.

\section{EL SECTOR PORTUARIO SERGIPANO Y SU DINÁMICA RECIENTE: TRANSPORTE DE CARGAS Y GARGALOS INFRAESTRUCTURALES}

\section{Resumen}

El transporte marítimo contribuye con los flujos de mercancías en el espacio y permite articular diversas ciudades, regiones y países, siendo importante para el desarrollo económico. El estado de Sergipe presentó mayor inserción económica a nivel regional y nacional en la última década, sin embargo, posee un sector portuario poco dinámico que perjudica el comercio, las redes y el efecto multiplicador interno. Ante este contexto, se busca realizar un

\footnotetext{
${ }^{1}$ Professor adjunto do Departamento de Geografia e docente permanente do Programa de Pós-graduação em Geografia (PPGEO), da Universidade Federal de Sergipe (UFS), campus de São Cristóvão. E-mail: nelfelipejr@hotmail.com.
}

Sociedade e Território - Natal. Vol. 29, N. 2, p. 30-48, Jul./Dez. de 2017. 
análisis sectorial, considerando la relación entre transporte marítimo, logística y dinámica económica, además de destacar los principales cuellos de botella existentes.

Palabras clave: sector portuario, transporte marítimo, mercancías, cuellos de botella.

\section{INTRODUÇÃO}

Os portos são resultantes da conjunção dos aspectos naturais, econômicos, políticos e humanos. O modal hidroviário fomenta a economia regional e nacional, a política econômica adotada pelo Estado gera repercussões nos fluxos hidroviários, o crescimento das redes e dos fluxos marítimos (cabotagem e longo curso) estimula a criação de empregos em diferentes setores (agropecuária, indústria, serviços e comércio), entre outros.

Os portos, os terminais privados, o transporte marítimo, a logística e as estratégias competitivas exercem influência na movimentação de cargas e na circulação do capital. Quanto mais rapidamente circula o capital, ou seja, quanto maior é a sua velocidade de rotação, menor é a estocagem de cargas e maior é a acumulação. Portos e terminais modernos atraem mercadorias de importação e exportação, gerando reflexos macroeconômicos positivos em âmbitos regional e nacional.

O transporte marítimo não representa um fim em si mesmo, ou seja, é um meio de servir a outros objetivos e outras demandas. A atividade produtiva é, em parte, dependente do transporte marítimo para conquistar mercados externos, ao passo que a cabotagem tem como objetivo principal subsidiar a cadeia de suprimentos interna. O sistema de transportes e, em especial, o modal marítimo é, por um lado, um reflexo da economia regional/nacional e, por outro, um fator que impulsiona o desenvolvimento. O transporte marítimo de cargas é subsidiário à produção e, ao mesmo tempo, importante para completar a rotatividade do capital.

As tecnologias ligadas à circulação, a grande capacidade dos navios cargueiros e a otimização logística geram importantes repercussões no transporte e no comércio. Grandes quantidades de cargas, atualmente, podem ser transportadas em menos tempo e com custos mais baixos, aparecendo sucessivamente no mercado (reabastecimento rápido do estoque), não sendo necessário, portanto, a armazenagem em larga escala.

O escoamento de produtos no território brasileiro através da cabotagem supre parte das demandas internas. Apesar das condições naturais existentes, a cabotagem é pouco utilizada em Sergipe e no Brasil. O transporte marítimo de longo curso (internacional), por 
sua vez, é responsável por grande parte das compras e vendas externas do país - em 2015, as exportações via marítima representaram 96\% do total e as importações 89\% (SECEX, 2017).

Diante disso, o presente trabalho analisa o setor portuário de Sergipe, relacionando com a dinâmica econômica estadual, a logística, as modernizações, os pontos de estrangulamento e os fluxos de mercadorias. A atividade portuária é fundamental para o desenvolvimento econômico do estado, porém a reduzida modernização do Terminal Marítimo Inácio Barbosa (TMIB) prejudica os investimentos, os empregos e a renda. O texto está dividido em duas partes, quais sejam: dinâmica econômica e o setor portuário de Sergipe, e as estratégias competitivas do setor marítimo brasileiro e as limitações do TMIB.

Esse artigo é resultado da pesquisa realizada na Universidade Federal de Sergipe (UFS) sobre o setor portuário e o transporte marítimo no estado. No que tange aos procedimentos metodológicos utilizados, têm-se: a) pesquisa bibliográfica (referente à temática econômica e, principalmente, ao transporte marítimo e sistema portuário, juntamente com pesquisas em sites da internet, revistas, jornais etc.); b) trabalhos de campo (no Terminal Marítimo Inácio Barbosa - TMIB); c) entrevistas (com profissionais que trabalham no TMIB); d) coleta de dados (no TMIB, na Agência Nacional de Transportes Aquaviários ANTAQ, na Secretaria de Comércio Exterior - SECEX etc.); e) produção de tabelas (a partir dos dados estatísticos obtidos).

\section{DINÂMICA ECONÔMICA E O SETOR PORTUÁRIO DE SERGIPE}

Ao reduzir o tempo gasto na circulação, aumenta-se a velocidade da reprodução do capital, o funcionamento dos meios de produção será potencializado, eleva-se a produtividade e há incremento na extração de mais-valia (MARX, 2005). Os avanços ligados ao setor portuário e ao transporte marítimo (logística, comunicações, instalações e tecnologias) permitem o escoamento de cargas em menos tempo e com maior segurança, por conseguinte, há baixo risco de perda dos produtos, prejuízo por parte dos produtores e atraso na entrega dos bens.

O Estado possui função relevante no que tange ao incremento (ou não) do processo de circulação do capital e de desenvolvimento econômico, já que a expansão das infraestruturas de transporte, comunicação e energia (destaque para o fomento da intermodalidade, dos portos e do transporte marítimo), as políticas setoriais e outros, são importantes para acelerar a rotatividade do capital e satisfazer as demandas econômicas e sociais (MARX; RANGEL, 2005).

Sociedade e Território - Natal. Vol. 29, N. 2, p. 30-48, Jul./Dez. de 2017. 
Através das inversões estatais, o poder público condiciona os investimentos privados de duas formas: a) imediatamente: é resultado dos atrativos gerados a partir das inversões em infraestruturas (transportes, energia etc.), sendo representado pelos investimentos produtivos; b) indiretamente: pela ação que seus gastos, mais os recursos privados, exercem sobre a demanda. A influência sobre a demanda total (inversões, reinvestimentos e consumo) é acelerada e se multiplica (RANGEL, 2005). Assim, por exemplo, quando há investimentos em um porto, estimulam-se as inversões do capital privado e, consequentemente, são gerados empregos e renda.

A expansão do transporte marítimo reduz o tempo gasto com a circulação das cargas no espaço, possibilitando a conquista de mercados distantes geograficamente (importações e exportações). A logística corporativa (entendida como planejamento, gestão, estratégias de transporte e armazenamento), por sua vez, permite atenuar os pontos de estrangulamento existentes no sistema portuário e marítimo que prejudicam a fluidez no escoamento, o cumprimento dos prazos de entrega e a rapidez na circulação do capital (SILVEIRA, 2009). No Brasil, o aprimoramento da logística por parte das empresas é mais rápido do que a melhoria dos fixos (infraestruturas).

O crédito (capital passível de ser emprestado), quando está disponibilizado de maneira abundante e barata (juros reduzidos), fomenta a economia e a circulação do capital. Inversões em infraestruturas permitem impulsionar o efeito multiplicador interno, com reflexos positivos na produção, na demanda por bens duráveis e não duráveis e no comércio (RANGEL, 2005).

Com o aprimoramento dos meios de transportes e a expansão dos fixos (mediante investimentos públicos e privados), são gerados empregos e renda (construção civil, indústrias de base, bens de capital etc.), tem-se um avanço quantitativo e qualitativo da circulação no espaço, há uma reposição mais rápida das mercadorias (destaque aos portos secos e terminais retroportuários) e, com a utilização dos contêineres, permite-se o escoamento de produtos com maior segurança.

Como nos momentos de crise há queda no consumo, nos fluxos marítimos e nas trocas internacionais, é imprescindível a realização de investimentos infraestruturais por parte do Estado, pois, dessa maneira, são estimulados diversos setores da economia (construção civil pesada, indústrias de base, bens de capital etc.) e se garante o nível de emprego e renda. Os instrumentos de política econômica devem criar condições para amenizar os efeitos da crise externa e servirem como medidas anticíclicas. A depressão gerada no centro do sistema Sociedade e Território - Natal. Vol. 29, N. 2, p. 30-48, Jul./Dez. de 2017. 
capitalista reduz a capacidade de importação, assim, historicamente o Brasil conseguiu suprir parte das demandas internas sob o mecanismo de substituição das importações (RANGEL, 2005).

O sistema portuário e marítimo brasileiro é caracterizado pela desregulamentação, bem como pela existência de oligopólio estrangeiro, sendo intensificado pela legislação neoliberal criada na década de 1990 (Lei 8.630/93 - Lei dos Portos), mitigando a reserva de mercado para os armadores nacionais e abrindo o setor para o grande capital estrangeiro. Os principais armadores que atuam nos portos e terminais do país são: Hamburg Süd (Alemanha), Maersk (Dinamarca), Mediterranean Shipping Company (MSC) (Itália/Suíça), Aliança (pertence à Hamburg Süd, Alemanha), CMA/CGM (França), Mitsui/OSK Lines (Japão), Cosco (China), Evergreen (Taiwan), China Shipping (China) e Hyundai (Coreia do Sul) (ANTAQ, 2016).

A logística privada e as infraestruturas possuem uma relação de coexistência, contudo, possuem significados distintos. Em muitos casos, as estratégias logísticas atenuam os pontos de estrangulamento existentes no sistema de transportes, sem que isso represente melhorias nos fixos. Assim, adotar novas rotas - mais curtas, com maior fluidez e com melhores condições de tráfego e sinalização - influencia os custos de transporte e garante maior segurança às mercadorias.

Os avanços ligados ao setor portuário e ao transporte marítimo (logística, comunicações, equipamentos, infraestruturas, tecnologias, estratégias, sistema normativo etc.) permitem o escoamento de cargas em menos tempo e com maior segurança. No Brasil prevalece a logística privada (gestão e estratégias de transporte e armazenamento) em relação à logística de Estado (planejamento visando expandir as infraestruturas no território).

O transporte marítimo de cabotagem articula portos localizados em um mesmo país, todavia, no Brasil ainda é incipiente esta modalidade de transporte em comparação ao modal rodoviário. A grande dimensão territorial brasileira e sua extensa costa litorânea (mais de oito mil quilômetros) criam condições propícias à cabotagem, porém há um predomínio exacerbado do transporte de cargas por caminhões (ainda que este seja importante para garantir o sistema "porta a porta"). A cabotagem no Brasil é realizada, principalmente, entre portos distantes geograficamente, caso, por exemplo, da articulação entre Santos/SP e Rio Grande/RS, e Paranaguá/PR e Suape/PE. 
Fomentar a cabotagem e o longo curso é importante para racionalizar o setor de transportes no país, mitigar o Custo Brasil ${ }^{2}$, aumentar a competitividade dos produtos nacionais, reduzir o preço final dos bens, arrefecer os congestionamentos de caminhões nos acessos dos principais portos marítimos brasileiros, impulsionar as redes e os fluxos de mercadorias, entre outros. Além disso, a expansão da cabotagem gera demanda na indústria naval brasileira, contribuindo, assim, com a geração de empregos e renda.

Principalmente entre 2003 e 2013, mesmo sem haver grandes rupturas, houve uma importante recuperação da economia nacional, com base na expansão do crédito, nos investimentos em infraestruturas (Programa de Aceleração do Crescimento - PAC), na diversificação das parcerias comerciais e outros. Estas ações, pautadas no planejamento e nos gastos/inversões públicos, criaram condições para elevação dos fluxos marítimos, principalmente de longo curso.

Houve a expansão das relações Sul-Sul (periferia-periferia), com destaque às parcerias comerciais brasileiras estabelecidas com países da África (Egito, Angola, Moçambique etc.), do Oriente Médio (Irã), do Leste Asiático (China e Índia, principalmente), do Leste Europeu (Polônia, Bulgária etc.), da América Latina (Peru, Venezuela, Cuba e outros), além de valorizar o Mercosul para o desenvolvimento do Brasil e das demais nações. Essa estratégia possui dois aspectos relevantes, quais sejam: a) indica uma postura anti-imperialista (de antagonismo à hegemonia dos Estados Unidos, sobretudo no contexto latino-americano); b) permitiu amenizar os impactos negativos da crise econômica internacional no país.

A recuperação da economia brasileira entre 2003 e 2013 gerou reflexos importantes em Sergipe, com destaque ao crescimento do emprego, da renda e do consumo. Como consequência, o estado apresentou maior inserção econômica em âmbitos regional e nacional na última década, todavia, possui um setor portuário pouco dinâmico que prejudica os fluxos, as redes e o desenvolvimento regional.

O fomento do comércio exterior brasileiro e a maior diversificação das parcerias comerciais (fluxos Sul-Sul) geraram reflexos no transporte marítimo e no setor portuário nacional, com aumento da demanda por inversões em infraestruturas, maior movimentação de cargas, contêineres e navios nos portos brasileiros, modernização (investimentos em

\footnotetext{
${ }^{2} \mathrm{O}$ "Custo Brasil" é um termo utilizado para indicar um conjunto de problemas estruturais e econômicos que prejudicam o investimento e o desenvolvimento nacional, como corrupção, burocracia excessiva, taxa de juros elevada, gargalos infraestruturais etc.
}

Sociedade e Território - Natal. Vol. 29, N. 2, p. 30-48, Jul./Dez. de 2017. 
instalações, equipamentos e softwares) e outros. Os principais portos e terminais privados do Brasil (Santos/SP, Rio de Janeiro/RJ, Itaguaí/RJ, Paranaguá/PR, Rio Grande/RS, Itajaí/SC, Itapoá/SC, Navegantes/SC, São Francisco do Sul/SC, Vitória/ES, Salvador/BA, Suape/PE, Pecém/CE, Itaqui/MA, Manaus/AM etc.) possuem muitas linhas com os mais importantes portos do mundo, como Xangai (China), Cingapura e Roterdã (Holanda).

O setor portuário sergipano possui capacidade antiociosa, limitando-se ao Terminal Marítimo Inácio Barbosa (TMIB), sendo articulado às rodovias SE-226, BR-235 e BR-101. O TMIB movimenta cargas de baixo valor agregado, como madeira, coque, ureia, cimento, trigo, fertilizantes, petróleo e derivados etc (tabela 1).

Tabela 1: Movimentação total de cargas no setor portuário de Sergipe (1995 e 2000-2015).

\begin{tabular}{c|c}
\hline ANO & QUANTIDADE (TONELADAS) \\
\hline 1995 & 2.499 .800 \\
\hline 2000 & 2.757 .367 \\
\hline 2001 & 2.693 .501 \\
\hline 2002 & 2.886 .743 \\
\hline 2003 & 2.657 .452 \\
\hline 2004 & 2.059 .612 \\
\hline 2006 & 2.102 .871 \\
\hline 2007 & 2.776 .689 \\
\hline 2008 & 2.794 .255 \\
\hline 2009 & 2.500 .764 \\
\hline 2010 & 1.179 .484 \\
\hline 2011 & 885.558 \\
\hline 2012 & 896.035 \\
\hline 2013 & 1.837 .524 \\
\hline 2014 & 1.033 .652 \\
\hline 2015 & 984.855 \\
\hline
\end{tabular}

Fonte: Agência Nacional de Transportes Aquaviários (ANTAQ), 2016.

O TMIB deveria receber maiores inversões para fomentar a dinâmica da Região Metropolitana de Aracaju/SE e do estado de Sergipe, todavia, o terminal é subaproveitado e depende exclusivamente das conexões rodoviárias (principalmente da BR-101 e BR-235). Uma ligação ferroviária eficiente seria importante para expandir a intermodalidade e a movimentação de mercadorias, sobretudo de grãos, farelos, fertilizantes e carga geral.

Maiores investimentos no setor portuário de Sergipe são necessários para fomentar a demanda efetiva, os empregos, a renda, o efeito de aglomeração de atividades (empresas transportadoras, agenciadores de cargas, estaleiros, armadores, centros de distribuição atacadistas e varejistas (CDs), indústrias etc.). Todavia, a falta de modernização e o 
subaproveitamento do TMIB prejudicam a economia e a sociedade sergipana, estrangulando o desenvolvimento do estado. Tais inversões possibilitariam estimular a retomada da geração de empregos formais na Região Metropolitana de Aracaju, mitigando, assim, os reflexos negativos da crise econômica. O TMIB tem potencial para expansão, com destaque à criação de uma retroárea de apoio, bem como concessões de terminais (granéis, sólidos, granéis líquidos e carga geral).

Entre 1995 e 2008 houve pequenas variações na movimentação de cargas pelo terminal, porém verificam-se quedas mais expressivas a partir de 2009 (principalmente nos anos de 2010, 2011 e 2014) (tabela 1), devido à recessão econômica internacional, à desaceleração da economia nacional e à modernização de outros portos do Nordeste (sobretudo Suape/PE e Pecém/CE). Além disso, há uma preferência dos armadores em movimentar mercadorias nos portos/terminais mais modernos (equipamentos, profundidade de atracação, cais e berços etc.), pois possuem condições de receber maiores navios de cargas. Tal fato reduz o custo por parte dos armadores e maximiza a utilização da capacidade dos navios (substituição dos navios pequenos e médios pelos grandes conteineros, graneleiros, petroleiros e mistos).

Em geral, os produtos movimentados pelo TMIB possuem baixo valor agregado, sendo reflexo da dinâmica econômica estadual e da reduzida modernização setorial. A carência de equipamentos avançados e a falta de ampliação da área do terminal prejudicam a movimentação de bens de médio/alto valor em contêineres (tabela 2).

Tabela 2: Principais mercadorias movimentadas no Terminal Marítimo Inácio Barbosa (toneladas), 2015.

\begin{tabular}{|c|c|c|c|c|c|}
\hline \multicolumn{4}{|c|}{ LONGO CURSO } & \multirow{2}{*}{\multicolumn{2}{|c|}{ CABOTAGEM }} \\
\hline \multicolumn{2}{|c|}{ Exportações } & \multicolumn{2}{|c|}{ Importações } & & \\
\hline Cargas & Quantidades & Cargas & Quantidades & Cargas & Quantidades \\
\hline $\begin{array}{l}\text { Fertilizantes } \\
\text { e adubos }\end{array}$ & 190.754 & $\begin{array}{l}\text { Coque de } \\
\text { petróleo }\end{array}$ & 503.554 & \multirow{3}{*}{ Trigo } & \multirow{3}{*}{35.182} \\
\hline \multirow[b]{2}{*}{ Cimento } & \multirow[b]{2}{*}{107.008} & Trigo & 86.374 & & \\
\hline & & $\begin{array}{l}\text { Químicos e } \\
\text { inorgânicos }\end{array}$ & 43.551 & & \\
\hline
\end{tabular}

Fonte: Agência Nacional de Transportes Aquaviários (ANTAQ), 2016.

A movimentação de cargas no Terminal Marítimo Inácio Barbosa (TMIB) é pouco expressiva (tabelas 2 e 3 e imagens 1, 2 e 3), principalmente quando se compara a outros portos e terminais do país, sendo importante sua expansão e modernização para atender as 
demandas internas e externas. Fomentar o setor portuário e marítimo é imprescindível para o desenvolvimento regional e nacional, porém os insuficientes investimentos públicos e privados e o modelo de concessão inadequado (Estado não regulador) prejudicam a economia sergipana.

Tabela 3: Origem e destino da cabotagem e do longo curso no TMIB, 2015.

\begin{tabular}{l|c}
\hline \multicolumn{2}{c}{ CABOTAGEM } \\
\hline Rotas & Quantidades (toneladas) \\
\hline Alagoas - Sergipe & 21.412 \\
\hline Ceará - Sergipe & 25.724 \\
\hline Espírito Santo - Sergipe & 155.747 \\
\hline Rio Grande do Sul - Sergipe & 35.182 \\
\hline \multicolumn{2}{|c}{ LONGO CURSO } \\
\hline Rotas & Quantidades (toneladas) \\
\hline África - Sergipe & 71.482 \\
\hline América do Norte - Sergipe & 447.392 \\
\hline América do Sul - Sergipe & 216.448 \\
\hline Ásia - Sergipe & 41.592 \\
\hline Europa - Sergipe & 154.327 \\
\hline
\end{tabular}

Fonte: Terminal Marítimo Inácio Barbosa (TMIB), 2016.

Imagem 1: Instalações do Terminal Marítimo Inácio Barbosa (TMIB), 2015.

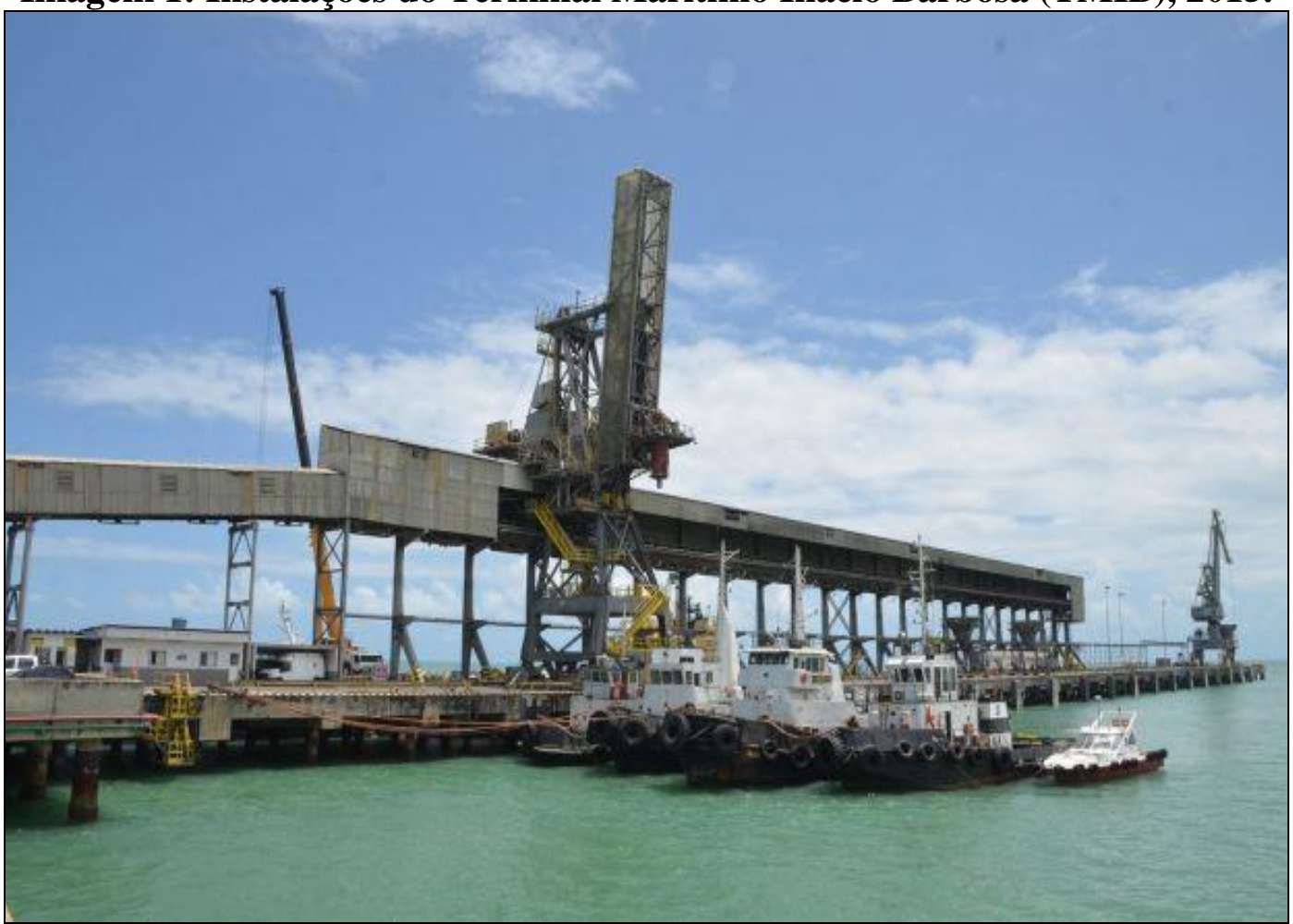

Fonte: Terminal Marítimo Inácio Barbosa (TMIB), 2015.

Sociedade e Território - Natal. Vol. 29, N. 2, p. 30-48, Jul./Dez. de 2017. 
Imagem 2: Navio atracado no Terminal Marítimo Inácio Barbosa (TMIB), 2015.

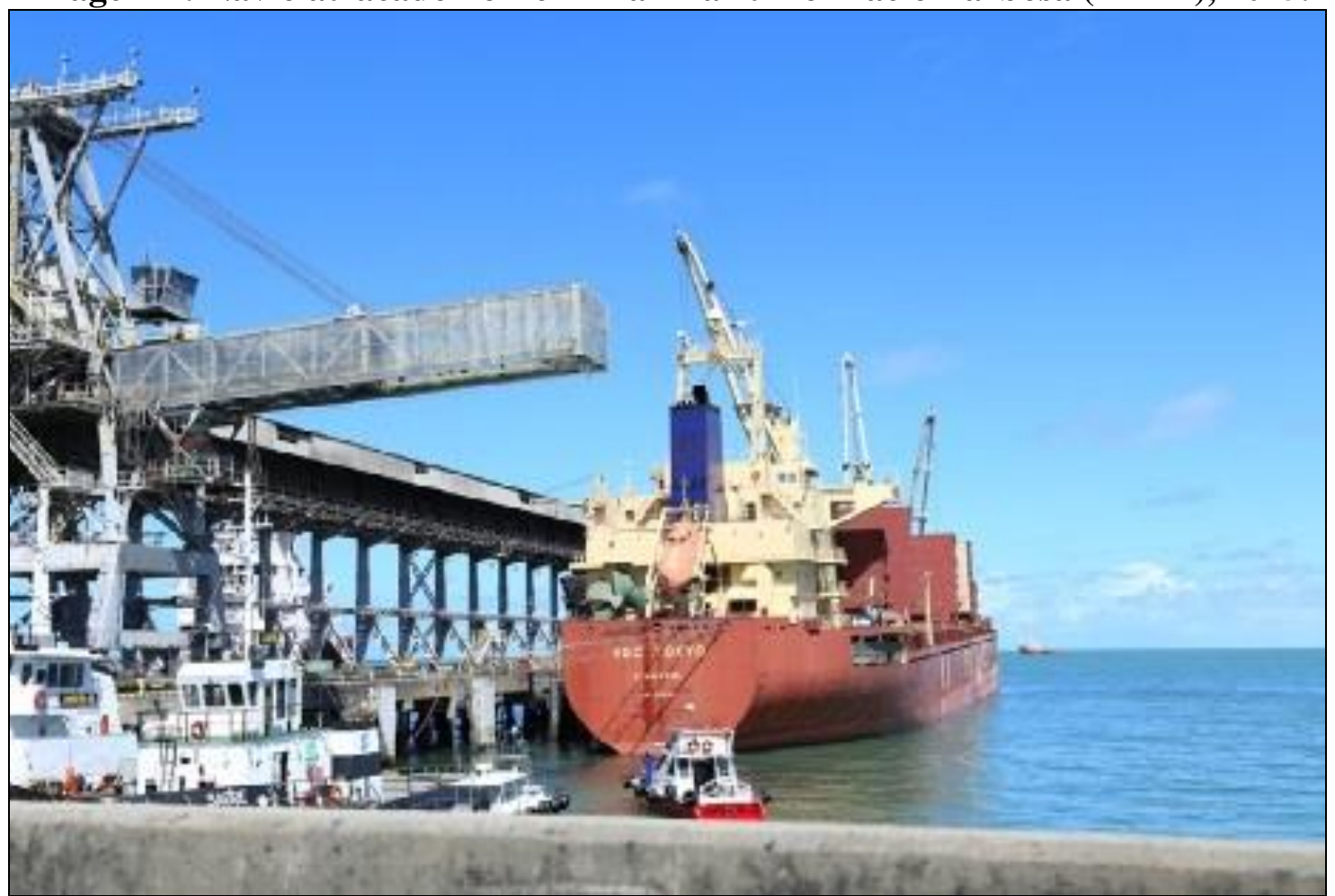

Fonte: Terminal Marítimo Inácio Barbosa (TMIB), 2015.

Imagem 3: Fiscalização da carga no Terminal Marítimo Inácio Barbosa (TMIB), 2015.

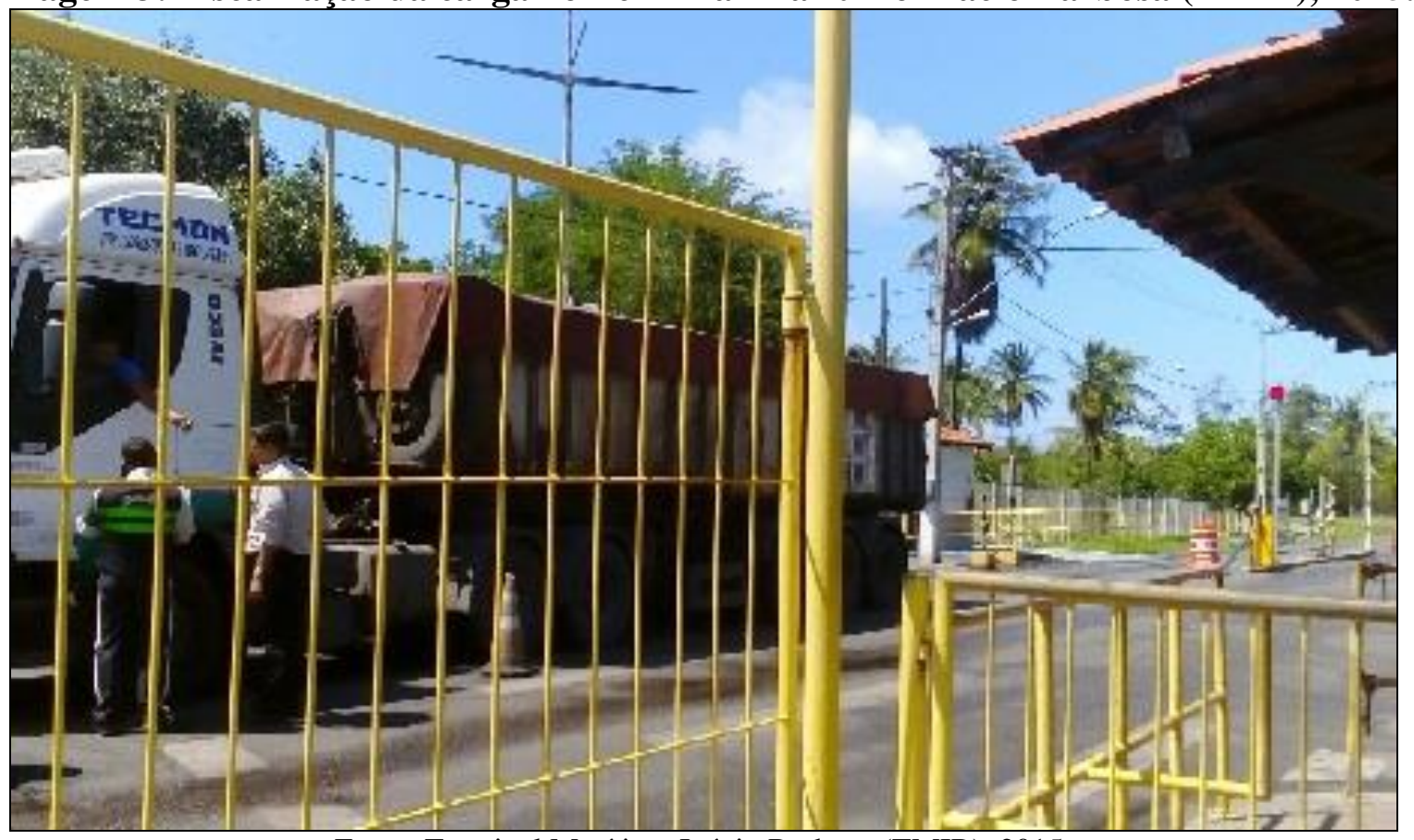

Fonte: Terminal Marítimo Inácio Barbosa (TMIB), 2015.

Sociedade e Território - Natal. Vol. 29, N. 2, p. 30-48, Jul./Dez. de 2017. 
A hinterlândia do Terminal Marítimo Inácio Barbosa compreende diversos estados brasileiros, como Sergipe, Alagoas, Ceará, Espírito Santo e Rio Grande do Sul. No que tange às trocas internacionais do TMIB, estas compreendem a África, a América do Norte, a América do Sul, a Ásia e a Europa, com predomínio dos Estados Unidos e dos países do Mercosul (tabela 3). No que tange ao estado de Sergipe, destacam-se os sucos concentrados e os fertilizantes como os principais produtos exportados e importados, respectivamente (tabela 4).

Tabela 4: Principais produtos exportados e importados por Sergipe, 2015.

\begin{tabular}{l|c|l|c}
\hline \multicolumn{1}{c|}{ EXPORTAÇÃO } & PORCENTAGEM & \multicolumn{1}{|c|}{ IMPORTAÇÃO } & PORCENTAGEM \\
\hline Sucos de laranja & $62,3 \%$ & $\begin{array}{l}\text { Insumos químicos } \\
\text { (principalmente fertilizantes) }\end{array}$ & $27,3 \%$ \\
\hline Sucos de abacaxi & $8,2 \%$ & Trigo & $11,8 \%$ \\
\hline Outros cítricos & $3,4 \%$ & Coque de petróleo & $10,2 \%$ \\
\hline Açúcares & $6 \%$ & $\begin{array}{l}\text { Máquinas para fabricação de } \\
\text { recipientes de vidro }\end{array}$ & $3,7 \%$ \\
\hline Calçados & $7,8 \%$ & Aparelhos e circuitos elétricos & $4,0 \%$ \\
\hline Outros & $12,5 \%$ & Outros & $47,9 \%$ \\
\hline
\end{tabular}

Fonte: Observatório de Sergipe, 2016.

No que tange ao Programa de Aceleração do Crescimento (PAC) no estado de Sergipe, destaca-se a duplicação da BR-101, sendo relevante para o aumento da fluidez, das interações espaciais e do efeito multiplicador interno. As concessões de trechos à Engenharia do Exército elucidam avanços nas obras em comparação às concessões a empresas privadas (principalmente em relação à rapidez e término das construções).

Entre 2011 e 2016, todas as inversões em transportes no estado de Sergipe se concentraram no modal rodoviário (aproximadamente 1 bilhão de reais) (AGÊNCIA SERGIPE DE NOTÍCIAS, 2017), assim, infere-se que as ferrovias e o setor portuário continuarão apresentando os gargalos que prejudicam a modernização setorial e o desenvolvimento regional. Fomentar a intermodalidade e a dinâmica portuária é essencial para impulsionar os fluxos de cabotagem e longo curso e o efeito multiplicador interno.

Ademais, seria interessante estimular a indústria naval em Sergipe (estaleiros), gerando reflexos positivos no emprego e na renda. Há uma demanda potencial no estado, principalmente em relação às atividades da Petrobras (petróleo, gás natural e derivados). Esse é um setor estratégico para o desenvolvimento regional e nacional, pois possui grande capacidade de atrair atividades diversas, especialmente serviços avançados de suporte offshore e onshore. 
Em 2015, a movimentação portuária de cargas em Sergipe evidencia a relevância da produção de cítricos para atender o mercado nacional e internacional (tabela 4). Muitos desses produtos, principalmente aqueles transportados em contêineres, são movimentados em portos de outros estados do Nordeste, sobretudo, em Salvador/BA e Suape/PE.

No estado de Sergipe, as principais empresas são: Petrobras, Maratá, Indústria de Móveis Cequipel Paraná, Adubos Sudoeste, Calçados Vulcabrás Azaleia, Leite de Rosas, Sabe Alimentos, Votorantim, Movesa, Mabel Alimentos, Sergipe Industrial (SISA), Nortista, Companhia Industrial de Celulose e Papel (CICP), Fábrica de Fertilizantes (FAFEN), Heringer Fertilizantes, Multigrain, Fertinorte, Motrisa, além dos centros de distribuição atacadista e varejista (Atacadão e G Barbosa). Todavia, há carência de um setor industrial de maior tecnologia, como bens de capital, equipamentos eletrônicos e de informática etc., sendo importante para o efeito multiplicador interno.

A transferência de recursos ociosos para o setor portuário (antiocioso) é imprescindível para o desenvolvimento econômico de Sergipe e do país, visto que estimula os investimentos do capital privado (instalação de terminais intermodais, por exemplo), gerando resultados econômicos e sociais positivos, especialmente na geração de empregos e renda (RANGEL, 2005).

Além disso, é fundamental haver um modelo de concessão de serviços públicos à iniciativa privada sob as bases de um Estado regulador (poder concedente e credor hipotecário). A antiga Lei dos Portos (Lei n. 8.630/93) e a lei geral que regulamenta as concessões de serviços públicos no Brasil (Lei n. 8.987/95) são pautadas no Estado-mínimo (RANGEL, 2005). Esse modelo liberal de concessão prejudicou/prejudica a atuação estatal e a modernização do TMIB, com reflexos negativos na economia sergipana. Apesar da Nova Lei dos Portos (Lei n. 12.815/2013), ainda não houve importantes mudanças na dinâmica do TMIB, permanecendo a sua reduzida competitividade.

\section{AS ESTRATÉGIAS COMPETITIVAS DO SETOR MARÍTIMO BRASILEIRO E AS LIMITAÇÕES DO TMIB}

A Lei n. 8.630/93 (Lei dos Portos) mudou o marco regulatório do setor portuário brasileiro. Seus principais objetivos eram: a) promover a descentralização do sistema portuário e marítimo brasileiro, inclusive através da estadualização e da municipalização dos portos (este fato foi consolidado a partir da criação da Lei n. 9.277/96); b) permitir que as operações portuárias e a movimentação de cargas fossem realizadas pelo capital privado Sociedade e Território - Natal. Vol. 29, N. 2, p. 30-48, Jul./Dez. de 2017. 
(tinha-se, claramente, a intenção de reduzir os encargos e gastos estatais); c) fomentar a modernização portuária e do transporte marítimo de cargas, principalmente através da aquisição de novos equipamentos e novas tecnologias pelo setor privado; d) permitir a exploração de cargas de terceiros em terminais de uso privativo; e) promover a concorrência no segmento para, em tese, levar à redução das tarifas de movimentação (tal fato acabou não ocorrendo, visto que formou-se um oligopólio estrangeiro e, portanto, as tarifas de movimentação variam muito pouco); f) promover a redução dos custos com trabalhadores portuários (houve muitas demissões no setor).

As concessões ligadas ao transporte marítimo de cargas refletem a frágil atuação do poder público, das Companhias Docas, das Administrações Portuárias e da Agência Nacional de Transportes Aquaviários (ANTAQ) na imposição de metas às concessionárias de transporte marítimo e de terminais, investimentos a serem realizados, fiscalização, liberdade de concorrência (muitas vezes os grandes armadores e os operadores de terminais pressionam o poder público no sentido de evitar a atuação de novas empresas no setor), "cartelização" do preço do frete e oligopólio estrangeiro.

Ocorreram importantes transformações no transporte de cargas nas duas últimas décadas, tanto em relação às infraestruturas quanto à gestão logística e às operações. A maior integração econômica e comercial do Brasil a partir da década de 1990 gerou repercussões no setor marítimo nacional. A modernização portuária é relevante para atender as demandas internas e externas (importações e exportações), com articulação entre os transportes, as comunicações e as informações. A incorporação de novas tecnologias (equipamentos, softwares etc.) aumentou a eficiência e a produtividade portuária.

A participação do capital privado no setor portuário fomentou a modernização setorial. Nos principais portos e terminais privados do país, destacam-se os Ship Loaders automatizados (dutos de sucção), STS (Ship to Shore Crane) (portêineres), RTG (Rubber Tyres Gantry) (transtêineres), MHC (Mobile Habour Crane) (guindastes), Reach Stackers (empilhadeiras), Terminal Tractors (veículos especiais para movimentar contêineres), softwares (Cosmos e Navys), scanners, contêineres especializados para cada tipo de mercadoria (granel sólido, granel líquido, frigoríficos etc.), navios Full Containers (conteineros), graneleiros e mistos (líquidos e sólidos) de grande capacidade, sistema ISPS Code (câmeras e controle de pessoas, veículos e cargas), entre outros.

No que tange à Lei n. 12.815/2013 (Nova Lei dos Portos), esta possui como critério de concessão a quantidade de inversões a serem realizadas pelo capital privado e não o valor pago Sociedade e Território - Natal. Vol. 29, N. 2, p. 30-48, Jul./Dez. de 2017. 
pela concessão (como era anteriormente). Portanto, um modelo mais adequado para fomentar a modernização do setor portuário e marítimo nacional.

Os navios porta-contêineres utilizados nas rotas marítimas entre o Brasil e o exterior estão cada vez maiores. Até o início da década de 2000, essas embarcações tinham capacidade para transportar 2,5 mil TEUs. Em 2015, a francesa CMA/CGM colocou nas linhas que transportam cargas para o Brasil o Tigris, um dos mais novos navios da empresa. Tem capacidade para movimentar 10,6 mil TEUs, sendo o maior porta-contêineres em operação no Brasil. Em alguns portos europeus e asiáticos trafegam navios de 12 mil e 15 mil TEUs (PORTAL MARÍTIMO, 2016).

Uma importante inovação tecnológica no setor marítimo brasileiro e mundial é o navio E-Ship 1 - navio cargueiro movido à energia eólica. Além da força dos ventos, usa motores a diesel e eletricidade. Esse navio já opera em portos brasileiros, especialmente do Sul e do Sudeste, como Santos/SP e Rio Grande/RS, por exemplo (CODESP, 2016).

Destacam-se ainda, os navios cargueiros parcialmente movidos por uma "pipa gigante". A "pipa" é controlada por computador e sua eficiência depende das condições climáticas, mas a vantagem do sistema informacional é que se aproveitam todas as direções do vento. A "pipa" não dispensa os motores, mas faz grande parte da função de movimentação dos navios. É uma inovação que contribui para arrefecer o custo do transporte marítimo, bem como a emissão de poluentes. Esse navio é utilizado em portos do Norte da Europa, devido aos fortes ventos existentes.

Em decorrência da crise econômica internacional, 5\% da frota mundial de navios estão parados e este fato, por sua vez, resultou em uma queda no preço do frete marítimo. Assim, os grandes armadores - caso da Maersk, Hamburg Süd, Mediterranean Shipping Company (MSC) etc. - estão adotando novas estratégias, caso da diminuição da oferta de navios para escoamento de cargas conteinerizadas, para induzir a um aumento relativo dos fretes. Além disso, as empresas estão realizando joints, ou seja, dois ou mais armadores estão transportando cargas em um mesmo navio, como forma de redução de custos e utilização da capacidade máxima dos grandes porta-contêineres (GUIA MARÍTIMO, 2016).

Outro aspecto importante se refere à substituição de navios de médio porte por outros maiores, fato que induz ao aumento da demanda e dos fluxos nos portos de maior profundidade e capacidade operacional. Um único navio conteinero (por exemplo, de 320 metros e capacidade de 9 mil TEUs) pode substituir dois navios menores de 150 metros e realiza uma quantidade maior de escalas, reduzindo custos com tripulação, combustível, Sociedade e Território - Natal. Vol. 29, N. 2, p. 30-48, Jul./Dez. de 2017. 
manutenção e outros. Os grandes armadores estão priorizando as principais rotas, os mercados consumidores em expansão (BRICS) e os hub ports (portos concentradores) (GUIA MARÍTIMO, 2016).

O setor portuário e marítimo brasileiro apresentou relevantes transformações nas duas últimas décadas, com destaque à modernização de diversos portos e terminais, difusão da utilização dos contêineres (térmicos, maiores, flexíveis etc.), Sistema de Posicionamento Global (GPS), softwares que controlam as operações dos terminais e enviam as informações em tempo real (real time), entre outros. Ou seja, a circulação no atual estágio do capitalismo se caracteriza pela intrínseca relação entre logística, transportes, comunicações e informações (SILVEIRA, 2009).

O nível de competitividade alcançado pelas empresas que atuam no setor marítimo está relacionado a fatores estruturais e organizacionais, isto é, às condições macroeconômicas, político-institucionais, regulatórias, infraestruturais, tecnológicas e logísticas. A capacidade de conquistar e expandir mercados pelas empresas significa a superação da concorrência a partir de forças internas (inovações tecnológicas, gestão logística, capacidade operacional, investimentos etc.) e externas (subsídios estatais, política de crédito, reserva de mercado, política tributária favorável e outros) (PORTER, 1989).

As estratégias ligadas ao setor marítimo significam a conquista de economias de escala e potenciais mercados consumidores, incremento dos fluxos a partir da expansão dos fixos e dos meios de transporte (navios), tecnologias de informação e comunicação (TICs), utilização de navios de grande capacidade de escoamento de cargas, escolha de portos que possuem melhores condições de atracação e movimentação, construção de terminais privados (longo curso e cabotagem), terminais alfandegados e portos secos, especialização dos navios e dos contêineres, terceirizações, intermodalidade, segurança ao longo do trajeto, redução e controle de estoques, entrega das encomendas nos prazos estabelecidos em contrato, decisões de investimentos pelas empresas em países que apresentam economias em expansão, registro dos navios em países que oferecem incentivos e isenções tributárias (Libéria, Panamá, Bahamas e Chipre, por exemplo), entre outros.

Vários aspectos como terceirizações no transporte rodoviário e marítimo (armadores), cumprimento dos prazos de entrega das mercadorias, redução dos riscos de acidentes, estocagem mínima, baixos salários etc. são verificados no setor portuário sergipano, entretanto, a reduzida modernização e a falta de uma política pública efetiva para fomento do setor portuário no estado prejudicam a economia e a geração de empregos e renda. A Sociedade e Território - Natal. Vol. 29, N. 2, p. 30-48, Jul./Dez. de 2017. 
estocagem mínima tem duas explicações: é uma estratégia para evitar a perda de parte das mercadorias, além de ser necessária devido à falta de espaço no terminal.

Destaca-se no Terminal Marítimo Inácio Barbosa a estratégia de redução dos custos com a mão de obra, especialmente através dos salários reduzidos, pois isso minimiza a queda dos lucros em momentos de diminuição da demanda interna e externa (recessão econômica). Essa estratégia é verificada em diversos portos e terminais do país, especialmente a partir dos anos de 1990.

O TMIB carece de modernização e é menos competitivo em comparação a outros portos mais dinâmicos do Nordeste e do Brasil. Como exemplo, tem-se o escoamento de granéis sólidos (grãos e farelos) do interior do Nordeste para os portos de Suape/PE e Pecém/CE, em detrimento do terminal sergipano, devido às limitações em suas operações.

Diversos gargalos prejudicam o setor portuário de Sergipe, como a excessiva burocracia, falta de ligação ferroviária ao TMIB, modelo neoliberal de concessão, reduzidos investimentos públicos e privados, morosidade na liberação dos recursos e nas obras, falta de dragagem para aprofundamento do canal de navegação e da área de atracação dos navios, reduzida incorporação de tecnologias (portêineres, transtêineres, softwares etc.), inexistência de um plano estratégico para fomentar o setor no estado, importância de dutovias articuladas ao terminal para transporte de petróleo e derivados, entre outros.

A busca incessante do capital pela redução de custos fomenta reestruturações internas e setoriais, como no TMIB, apresentando terceirizações ligadas à segurança, alimentação, fiscalização, contabilidade, transporte, armazenamento e outros. Ademais, destacam-se os grandes mercados consumidores (Estados Unidos, Europa e Ásia), os contratos com transportadores rodoviários de credibilidade, os afretamentos de navios estrangeiros, os joints (dois ou mais armadores transportam cargas em um mesmo navio), entre outros.

As principais empresas transportadoras rodoviárias que atuam no Terminal Marítimo Inácio Barbosa são a Meta e a Flex (transportam coque), a Transparaná e a Transpampa (escoamento de ácido sulfúrico), além da Asi (trigo e fertilizantes). A manutenção do terminal é realizada por empresas e trabalhadores terceirizados: Ipiranga (pinturas), Boy Serviços Marítimos (construção civil), Mendes e Ferreira (segurança portuária) e Lenel (controle de dados e fiscalização da entrada e saída de pessoas e caminhões).

As empresas Votorantim, Heringer, Multigrain, Fertinorte e Motrisa utilizam o TMIB para movimentar seus produtos, como cimento, coque, adubo, soja, trigo etc., já a Petrobras é a única empresa a utilizar contêineres no terminal, escoando alimentos refrigerados e não Sociedade e Território - Natal. Vol. 29, N. 2, p. 30-48, Jul./Dez. de 2017. 
refrigerados para suas plataformas de petróleo e gás natural em Sergipe. Ademais, para amenizar a queda de acumulação devido à recessão brasileira e internacional, a Valor Logística Integrada (VLI) - grupo que controla o TMIB - está, atualmente, realizando demissões de trabalhadores no terminal.

\section{CONSIDERAÇÕES FINAIS}

O sistema marítimo brasileiro é concentrado nos portos do Sul e do Sudeste, sendo responsáveis por grande parte das importações e exportações nacionais $(70 \%$ da movimentação de artigos industriais do país). O Porto de Santos/SP se destaca nos fluxos de bens industrializados e de contêineres (maior valor agregado), representando um quarto do comércio exterior do Brasil.

A dinâmica recente da economia sergipana gerou mudanças espaciais e sociais (produção, circulação, empregos, renda, consumo etc.). Todavia, o estado possui um setor portuário obsoleto, ou seja, com reduzida modernização, eficiência e competitividade. $\mathrm{O}$ TMIB é pouco competitivo quanto se compara a outros portos e terminais privados do Nordeste, assim, movimenta principalmente cargas de menor valor agregado. Portos mais dinâmicos, como Salvador/BA, Suape/PE e Pecém/CE transportam muitas cargas sergipanas devido às modernizações existentes (equipamentos, softwares, comunicações etc.).

Diversos são os gargalos existentes no setor portuário de Sergipe, quais sejam: reduzidas inversões públicas e privadas, falta de modernização (instalações, softwares e comunicações), reduzida profundidade da área de atracação, necessidade de expansão de cais e berços, construção de retroárea de apoio, intermodalidade deficiente, necessidade de expandir o modal ferroviário e sua conexão com o TMIB, modelo de concessão neoliberal (Estado não regulador), planejamento voltado exacerbadamente ao modal rodoviário, entre outros.

O fomento do setor portuário de Sergipe depende de vários fatores, quais sejam: presença do Estado como agente planejador e indutor, aumentar as inversões públicas e privadas, impulsionar a modernização tecnológica, realizar adequadas concessões de serviços públicos à iniciativa privada, estimular o carreamento de recursos ociosos ao setor (antiocioso), expandir os financiamentos a juros baixos, assegurar reserva de mercado e reduzir os afretamentos de navios estrangeiros, expansão das encomendas da Petrobras e da Transpetro na indústria naval brasileira (cabotagem e longo curso), reduzir a burocracia, 
acabar com a morosidade na liberação dos recursos públicos, acelerar a realização das obras infraestruturais e expansão da intermodalidade.

Apesar da reduzida modernização, algumas estratégias competitivas são verificadas no TMIB, como terceirizações no transporte rodoviário e marítimo (armadores), redução dos riscos de acidentes, estocagem mínima, baixos salários, rapidez na fiscalização e controle das cargas, entre outros. Ademais, destacam-se os produtos industrializados oriundos da Bahia, Pernambuco, Rio de Janeiro, São Paulo, Santa Catarina e Rio Grande do Sul, sendo escoados pelo modal rodoviário para atender o mercado sergipano.

A heterogeneidade é uma característica do sistema marítimo brasileiro. O estado de Santa Catarina possui diversos portos e terminais privados que "dividem" relativamente a demanda (desconcentração portuária), com destaque aos complexos especializados na movimentação de cargas conteinerizadas (Itajaí/SC, Navegantes/SC, Itapoá/SC e outros). Nos estados de São Paulo, Paraná e Rio Grande do Sul, verifica-se uma concentração da movimentação de mercadorias em um único porto (Santos/SP, Paranaguá/PR e Rio Grande/RS, respectivamente). No Nordeste, Pernambuco e Ceará apresentam novos complexos que estão "retirando" as cargas dos antigos portos, caso de Suape/PE e Pecém/CE. Em Sergipe, além da dependência do TMIB, este carece de ampliação e modernização para atender as demandas do estado.

Ademais, o TMIB poderia melhor atender as atividades industriais relacionadas ao petróleo e gás natural, minério de potássio (para a fabricação de fertilizantes), calcário (para a produção de cimento), móveis e cítricos em Sergipe. O estado é o quinto em produção e reserva de petróleo no Brasil e os serviços onshore e offshore (como transporte e armazenamento) possuem uma participação importante no valor agregado do setor terciário do estado.

\section{REFERÊNCIAS}

BRASIL. Agência Nacional de Transportes Aquaviários (ANTAQ). Dados estatísticos. Brasília, 2016.

eStado De SÃO PAUlo. Companhia Docas do Estado de São Paulo (CODESP). Santos, 2016.

ESTADO DE SERGIPE. Agência Sergipe de Notícias. Informações sobre o estado de Sergipe. Aracaju, 2017. Disponível em: http://agencia.se.gov.br/. Acesso em: janeiro/2017. 
FELIPE JUNIOR, Nelson Fernandes. Circulação, transportes e logística no setor portuário e marítimo brasileiro. Vila Velha: Above, 2014.

FELIPE JUNIOR, Nelson Fernandes. Dinâmica econômica e recentes transformações no transporte marítimo de cabotagem e longo curso no Brasil: alguns apontamentos sobre a modernização portuária no Estado de São Paulo. 2012. Tese (Doutorado em Geografia). Programa de Pós-Graduação em Geografia, UNESP, Presidente Prudente.

FROMM, Gary (Org.). Transporte e desenvolvimento econômico. Rio de Janeiro: Victor Publicações, 1968.

GUIA MARÍTIMO. Informações e dados sobre o setor portuário e marítimo. São Paulo, 2016. Disponível em: http://www.guiamaritimo.com.br/. Acesso em: outubro/2016.

KEYNES, John Maynard. A teoria geral do emprego, do juro e da moeda. São Paulo: Atlas, 1982.

OBSERVATÓRIO DE SERGIPE. Informações e dados estatísticos. Aracaju, 2016. Disponível em: http://www.observatorio.se.gov.br/. Acesso em: janeiro/2017.

PORTAL MARÍTIMO. Informações e dados sobre o setor portuário e marítimo. Rio de Janeiro, 2016. Disponível em: http://www.portalmaritimo.com/. Acesso em: novembro/2016.

PORTER, Michael Eugene. Estratégia competitiva: técnicas para análise de indústrias e da concorrência. Rio de Janeiro: Elsevier, 1986.

PORTER, Michael Eugene. Vantagem Competitiva: criando e sustentando um desempenho superior. Campus. Rio de Janeiro,1989.

RANGEL, Ignácio. Obras reunidas (v. 1 e 2). Rio de Janeiro: Contraponto, 2005.

SANTOS, Milton. A natureza do espaço: técnica e tempo, razão e emoção. São Paulo: Edusp, 2002.

SILVEIRA, Márcio Rogério (Org.). Circulação, transportes e logística: diferentes perspectivas. São Paulo: Outras Expressões, 2011.

TERMINAL MARÍTIMO INÁCIO BARBOSA (TMIB). Informações e dados estatísticos. Barra dos Coqueiros, 2016.

Recebido em Julho de 2017

Aprovado em Outubro de 2017

Publicado em Dezembro de 2017

Sociedade e Território - Natal. Vol. 29, N. 2, p. 30-48, Jul./Dez. de 2017. 